\title{
ANALISIS HUBUNGAN KOMPENSASI DAN DISIPLIN KERJA \\ KARYAWAN PADA PT. PERKEBUNAN NUSANTARA VI \\ UNIT USAHA RIMBO SATU KABUPATEN TEBO \\ (Studi Pada Bagian Buruh Panen Afdeling III)
}

\section{ANALYSIS OF COMPENSATION AND WORK DISCIPLINE RELATIONSHIP \\ EMPLOYEES AT PT. NUSANTARA VI PLANTATIONS \\ RIMBO BUSINESS UNIT ONE TEBO DISTRICT \\ (Study on the Harvest Labor Section of Afdeling III)}

\author{
Misra Yeni. R \\ Progam Studi Manajemen, Fakultas Ekonomi, Universitas Muara Bungo \\ Jl. Diponegoro No 27 Kelurahan Cadika, Kecamatan Rimbo Tengah Kabupeten Bungo, \\ Jambi 37211, Indonesia \\ yenimisra@gmail.com
}

\begin{abstract}
ABSTRAK
Tujuan dari penelitian ini adalah untuk mengetahui hubungan kompensasi dan disiplin kerja karyawan pada PT. Perkebunan Nusantara VI Unit Usaha Rimbo Satu Kabupaten Tebo (Studi Pada Bagian Buruh Panen Afdeling III).

Penelitian ini menggunakan jenis penelitian deskriptif kuantitaif, data yang digunakan adalah data primer dan data sekunder. Untuk teknik penelitian, peneliti menggunakan teknik wawancara, kuesioner, dan observasi. Untuk populasi dan sampel berjumlah 49 karyawan bagian buruh panen Afdeling III. Dengan teknik penarikan sampel menggunakan metode sampling jenuh. Kemudian jumlah responden yang mengisi kuesioner sebanyak 46 responden dan 3 kuesioner tidak kembali. Sedangkan pengujian hipotesis menggunakan analisis Korelasi Pearson Product Moment.

Berdasarkan hasil pengolahan data adapun hubungan antara kompensasi dan disiplin kerja karyawan adalah rendah. Ini di dapat dari hasil olah data uji analisis Korelasi Pearson Product Moment ( $\mathrm{r}$ ) dengan nilai sebesar 0,308 dengan tingkat probabilitas sebesar 0,000. Mengandung arti bahwa kompensasi mempunyai hubungan disiplin kerja karyawan sebesar 0,308 dan dikategorikan mempunyai hubungan yang rendah.

Kata Kunci : Kompensasi dan Disiplin Kerja Karyawan
\end{abstract}

\section{ABSTRACT}

The purpose of this study was to determine the relationship between compensation and work discipline of employees at PT. Perkebunan Nusantara VI Rimbo Satu Business Unit, Tebo Regency (Study on the Harvest Labor Section of Afdeling III).

This study uses quantitative descriptive research, the data used are primary data and secondary data. For the research technique, the researcher used interview, questionnaire, and observation techniques. For the population and sample, there are 49 employees of the Afdeling III harvest labor division. With the sampling technique using the saturated sampling method. Then the number of respondents who filled out the questionnaire as many as 46 respondents and 3 questionnaires did not return. While testing the hypothesis using the Pearson Product Moment Correlation analysis. 
Based on the results of data processing, the relationship between compensation and employee work discipline is low. This is obtained from the results of the analysis of the Pearson Product Moment Correlation analysis test $(r)$ with a value of 0.308 with a probability level of 0.000. It means that compensation has a relationship with employee discipline of 0.308 and is categorized as having a low relationship.

Keywords: Employee Compensation and Work Discipline

\section{PENDAHULUAN Latar Belakang}

Dunia bisnis sekarang dituntut menciptakan disiplin kerja karyawan yang tinggi untuk mengembangkan perusahaan. Keberhasilan perusahaan tersebut di pengaruhi oleh beberapa faktor, salah satu faktor penting adalah sumber daya manusia, karena sumber daya manusia merupakan pelaku dari keseluruhan tingkat perencanaan sampai dengan evaluasi yang mampu memanfaatkan sumber daya yang dimiliki oleh perusahaan.

Tercapainya tujuan perusahaan tidak hanya tergantung pada peralatan modern, sarana dan prasaranan yang lengkap, tetapi justru lebih tergantung pada manusia yang melaksanakan pekerjaan tersebut. Untuk menjamin tercapainya keselarasan tujuan perusahaan, pimpinan organisasi bisa memberikan perhatian dengan memberikan kompensasi, karena kompensasi merupakan bagian dari hubungan timbal balik antara organisasi dengan sumber daya manusia.

Sumber daya manusia dan tenaga kerja merupakan salah satu faktor utama untuk mencapai hasil yang maksimal dalam pencapaian tujuan suatu organisasi. Keberadaan tenaga kerja atau karyawan yang berkualifikasi perlu dikelola sebaik mungkin agar mereka dapat bekerja sesuai dengan fungsi dan tugasnya masingmasing. Untuk itu perusahaan harus menjalankan fungsi-fungsi manajemen sumber daya manusianya. Salah satu fungsi pendukungnya adalah kompensasi. Fungsi dari pemberian kompensasi ini bertujuan untuk memberikan imbalan yang layak atas kontribusi karyawan terhadap organisasi. $\begin{array}{ccc}\text { Menurut } & \text { Handoko } & (2002) \\ \text { kompensasi adalah pemberian } & \text { kepada }\end{array}$ karyawan dengan pembayaran financial sebagai balas jasa untuk pekerjaan yang dilaksanakan dan sebagai motivator untuk pelaksanaan kegiatan diwaktu yang akan datang. Dalam proses pemberian kompensasi sering terjadi perselisihan antara karyawan dengan perusahaan yang disebabakan oleh ketidak seimbangan antara hak dan kewajiban dari setiap tenaga kerja. Sedangkan menurut Hasibuan (2002) kompensasi adalah semua pendapatan yang berbentuk uang, barang, langsung atau tidak langsung yang diterima karyawan sebagai imbalan atas jasa yang diberikan kepada perusahaan. Dengan indikatornya yaitu, gaji, upah, upah insentif dan Benefit Service (kesejahteraan karyawan).

Pemberian kompensasi yang layak dan wajar akan mendorong peningkatan kedisiplinan dalam melaksanakan tugas dan kewajiban. Dengan adanya kedisiplinan kerja karyawan yang tinggi secara otomatis mempengaruhi tingkat pencapaian tujuan perusahaan. Perusahaan yang mempunyai karyawan dengan disiplin kerja yang tinggi akan mendorong aktivitas operasional perusahaan sehingga dapat mencapai tujuan dan sasaran yang telah di tetapkan perusahaan. Keberhasilan perusahaan atas kerja karyawan dalam mencapai tujuan yang maksimal, diperlukannya disiplin kerja karyawan.

Siagian (2008) disiplin merupakan hal yang harus ditanamkan dalam diri tiap karyawan. Kesadaran karyawan diperlukan dengan mematuhi peraturan peraturan yang berlaku. Disiplin adalah kerja yang baik agar mempercepat tujuan perusahaan, sedangkan untuk karyawan yang tidak 
disiplin akan memperlambat tujuan perusahaan. Menurut Mangkuprawira (2007) mengemukakan bahwa disiplin merupakan sifat seseorang karyawan yang secara sadar mematuhi aturan dan peraturan organisasi tertentu. Kedisiplinan sangat mempengaruhi kerja karyawan dan perusahaan, karena kedisiplinan sebagai bentuk latihan bagi karyawan dalam melaksanakan aturan-aturan perusahaan.

PT. Perkebunan Nusantara VI yang saat ini berkantor pusat di Kota Jambi dan mempunyai wilayah kerja di Provinsi Jambi dan Sumbar. Adalah BUMN perkebunan yang berdiri pada tahun 1979 yang bergerak dibidang perkebunan karet kemudian pada tahun 1997 beralih lah dari perkebunan karet ke perkebunan sawit. PT. Perkebunan Nusantara VI Unit Usaha Rimbo Satu Kabupaten Tebo mempunyai bagian dari wilayah kerja yaitu Afdeling I, Afdeling II, Afdeling III, Afdeling IV, dan Afdeling V. Afdeling berasal dari bahasa belanda yang artinya (Bagian). Kantor Afdeling III Unit Usaha Rimbo Satu Kabupaten Tebo adalah bagian dari wilayah kerja dari PT. Perkebunan Nusantara VI Unit Usaha Rimbo Satu Kabupaten Tebo. Terletak di Desa Wajah Deli, Kelurahan Pematang Sapat, Kecamatan Rimbo Bujang, Kabupaten Tebo.

Di kantor Afdeling III Unit Usaha Rimbo Satu Kabupaten Tebo terdapat karyawan dengan bagian masing-masing yaitu, karyawan bagian buruh panen, karyawan bagian pemeliharaan luar, dan Karyawan bagian pemupukan. Berdasarkan wawancara kepada Bapak M Agung Laksono selaku Asisten Adeling III mengatakan bahwa besarnya gaji yang diterima karyawan buruh bagian panen tidak sama dengan gaji yang diberikan kepada karyawan buruh bagian pemeliharaan luar dan karyawan buruh bagian pupuk. Dimana gaji karyawan buruh panen lebih kecil dibandingkan dengan karyawan buruh pemeliharaan luar dan karyawan buruh pupuk. Sementara dilihat pada tugas dan kewajiban karyawan buruh panen lebih besar. Di bandingkan dengan tugas dan kewajiban karyawan buruh bagian lainnya.

Ketika pemberian kompensasi berjalan dengan adil dan layak sesuai dengan perencanaannya maka tahapan selanjutnya yang diharapkan akan terjadi adalah peningkatan disiplin kerja karyawan bagian buruh panen. Ketika disiplin kerja karyawan bagian buruh panen telah tercapai maka perusahaan dapat mengukur sejauh mana peningkatan hasil kerja karyawan yang mereka capai. Hal inilah yang menjadi alur dasar penelitian yang akan dikembangkan oleh penulis, dimana penulis menduga adanya hubungan kompensasi dan disiplin kerja karyawan pada Bagian Buruh Panen Afdeling III.

Kantor Afdeling III Unit Usaha Rimbo Satu Afdeling III Kabupaten Tebo adalah bagian dari wilayah kerja dari PT. Perkebunan Nusantara VI yang bergerak di bidang perkebunan kelapa sawit, di bawah pimpinan Bapak $\mathrm{M}$ Agung Laksono. Kedisiplinan karyawan yang tinggi sangat lah di harapkan oleh PT. Perkebunan Nusantara VI Unit Usaha Rimbo Satu Afdeling III Kabuapten Tebo khususnya buruh panen, Pemberian kompensasi yang tidak mencukupi bagi karyawan bagian buruh panen tentu mempunyai hubungan terhadap disiplin kerja karyawan. Hasil wawancara dengan Bapak Santoso selaku mandor panen menyatakan bahwa terdapat indikasi belum optimalnya disiplin kerja karyawan pada PT. Perkebunan Nusantara VI Unit Usaha Rimbo Satu bagian buruh panen Afdeling III Kabupaten Tebo. Dimana berdasarkan wawancara dengan mandor panen mengatakan bahwa ketidak disiplinan kerja karyawan buruh panen tentu mempunyai hubungan dengan hasil kerja mereka yang dilihat pada data hasil produksi panen kelapa sawit yang mengalami fluktuasi pada tahun 2015.

\section{METODE PENELITIAN}

\section{Rancangan Penelitian}

$\begin{array}{ccr}\text { Objek } & \begin{array}{c}\text { penelitian ini } \\ \text { kuantitatif, }\end{array} & \begin{array}{r}\text { adalah } \\ \text { deskriptif }\end{array}\end{array}$ 
mengumpulkan,

mengola,

menyederhanakan, menyediakan dan menganalisis data kuantitatif (angkaangka) dan secara deskriptif (uraian kalimat) agar dapat memberikan gambaran yang jelas tentang fenomena-fenomena yang terjadi yang akan diteliti, Sugiyono (2012). Penelitian ini menggunakan metode survey dengan pendekatan deskriptif kuantitatif, metode survey yaitu mengambil sampel dari suatu populasi tentang menyakut fakta-fakta yang ditemui melalui kuisioner dan wawancara.

\section{Populasi dan Sampel}

Penelitian ini yang dijadikan sebagai populasinya berjumlah 49 orang karyawan PT. Perkebunan Nusantara VI Unit Usaha Rimbo Satu Kabupaten Tebo Bagian Buruh Panen Afdeling III.

Teknik penarikan sampel menggunakan metode sampling jenuh dimana anggota populasi digunakan sebagai sampel karena jumlah populasi relatif kecil Sugiyono (2011). Jadi jumlah populasi dijadikan sampel sebanyak 49 orang karyawan PT. Perkebunan Nusantara VI Unit Usaha Rimbo Satu Kabupaten Tebo Bagian Buruh Panen Afdeling III.

\section{Tehnik Analisa Data}

\begin{tabular}{llr}
\multicolumn{1}{c}{ Objek penelitian ini $\begin{array}{r}\text { adalah } \\
\text { kuantitatif, }\end{array}$} \\
$\begin{array}{l}\text { yaitu } \\
\text { meskriptif }\end{array}$ \\
mengumpulkan,
\end{tabular} menyederhanakan, menyediakan dan menganalisis data kuantitatif (angkaangka) dan secara deskriptif (uraian kalimat) agar dapat memberikan gambaran yang jelas tentang fenomena-fenomena yang terjadi yang akan diteliti, Sugiyono (2012). Penelitian ini menggunakan metode survey dengan pendekatan deskriptif kuantitatif, metode survey yaitu mengambil sampel dari suatu populasi tentang menyakut fakta-fakta yang ditemui melalui kuisioner dan wawancara.

Dalam analisis deskriptif ini peneliti menggunakan perangkat lunak (software SPSS versi 23). Sementara itu
Analisis statistik dimaksudkan untuk menguji hipotesis penelitian yang telah dirumuskan sebelumnyayaitu untuk mengetahui apakah ada hubungan kompensasi dan disiplin kerja karyawan pada pt. perkebunan nusantara vi unit usaha rimbo satu kabupaten tebo. Dalam hal ini, tehnik statistik yang digunakan adalah skala likert, maka variabel yang akan di ukur dijabarkan menjadi indikator variabel. Kemudian indikator tersebut dijadikan sebagai titik tolak untuk menyusun item-item instrument yang dapat berupa pertanyaan atau pernyataan, Sugiyono (2012).

Rentang Skala $=\frac{n(m-1)}{m}$

Dimana :

$\mathrm{n}$ = Jumlah Sampel

$\mathrm{m}=$ Jumlah Jawaban Item

\section{HASIL PENELITIAN DAN PEMBAHASAN}

Berdasarkan deskripsi dari indikator variabel kompensasi yaitu gaji, upah, upah insentif, dan benefit service (kesejahteraan karyawan), maka nilai ratarata yang di rekap memperoleh nilai sebesar 152,1 dengan kategori cukup baik. Kemudian dilihat dari indikator variabel disiplin kerja yaitu tepat waktu masuk kerja, tanggung jawab, tepat waktu dalam istirahat, mengerjakan pekerjaan dengan baik dan bertanggung jawab, dan tepat waktu pulang kerja. diperoleh nilai ratarata yang di rekap yaitu sebesar 180 dengan kategori baik.

Berdasarkan hasil pengolahan data hubungan variabel kompensasi dan disiplin kerja rendah. Hal ini di dapat dari hasil olah data uji Korelasi Pearson Product Moment dengan nilai sebesar 0,308 dengan kategori lemah. Analisisnya pada penelitian ini untuk variabel kompensasi tidak ada hubungan atau keterkaitan yang kuat dengan variabel disiplin kerja pada PT. Perkebunan Nusantara VI Unit Usaha Rimbo Satu Kabupaten Tebo (Studi pada bagian buruh panen Afdeling III). Karena setelah diteliti 
meski pun kompensasinya cukup baik tidak terdapat hubungan yang kuat pada disiplin kerjanya yang tetap baik. Hal ini sesuai dengan teori Mathis dan Jackson (2002) bahwa salah satu cara manajemen untuk meningkatkan kinerja, memotivasi dan meningkatkan disiplin kerja karyawan adalah melalui kompensasi, dalam hal ini juga (Fikriman dan Arif, 2017) menyatakan bahwa faktor upah sangat mempengaruhi produktivitas kinerja buruh panen sawit di PT. Megasawindo Perkasa I, sehingga kompensasi yang melalui upah sangat mempengaruhi produktivitas kinerja.

\section{KESIMPULAN DAN SARAN Kesimpulan}

Penelitian ini bertujuan untuk mengetahui hubungan kompensasi dan disiplin kerja karyawan pada PT. Perkebunan Nusantara VI Unit Usaha Rimbo Satu Kabupaten Tebo (studi pada bagian buruh panen Afdeling III). Berdasarkan hasil olahan data SPSS Versi 23 nilai Korelasi Pearson Product Moment dari variabel kompensasi dan disiplin kerja dengan diperoleh nilai $(r$ ) adalah 0,308 menunjukan bahwa kompensasi dan disiplin kerja memiliki hubungan dengan kategori lemah.

\section{Saran}

Berdasarkan kesimpulan di atas saran yang di tunjukan untuk PT. Perkebunan Nusantara VI Unit Usaha Rimbo Satu Kabupaten Tebo adalah sebagai berikut :

\section{Kepada Pihak Perusahaan}

sebaiknya pemberian kompensasi pada PT. Perkebunan Nusantara VI Unit Usaha Rimbo Satu Kabupaten Tebo Afdeling III khususnya bagian buruh panen lebih di tingkatkan, baik jenisnya seperti (gaji, upah, dan upah insentif) maupun besarnya nilai kompensasi.

\section{Kepada karyawan}

Kepada karyawan di PT. Perkebunan Nusantara VI Unit Usaha Rimbo Satu Kabupaten Tebo Afdeling III bagian buruh panen. Tetap mempertahankan dan menjaga prilaku kepatuhan atau disiplin kerja sesuai dengan peraturan perusahaan.

\section{DAFTAR PUSTAKA}

Fikriman, F., \& Herdiansyah, A. (2017). Faktor-faktor yang Mempengaruhi Produktivitas Tenaga Kerja Buruh Panen Buah Kelapa Sawit (studi Kasus pada Divisi I PT. Megasawindo Perkasa Ikecamatan Pelepat Kabupaten Bungo). JAS (Jurnal Agri Sains), 1(1).

Handoko, T. Hani,2002. Manajemen Personalia Dan Sumber Daya Manusia. BPFE. Yogyakarta

Hasibuan, Melayu S.P 2002. Manajemen Sumber Daya Manusia. Edisi Revisi, Cetakan Kedelapan. Jakarta : PT. Bumi Aksara

Mangkuprawira, 2007. Manajemen Mutu Sumber Daya Manusia, penerbit: Ghalia Indonesia Jakarta

Mathis dan Jackson.2002. Manajemen Sumber Daya Manusia, Buku 2, alih Bahasa Salemba Empat. Jakarta.

Siagian P. Sondang, 2008, Manajemen Sumber Daya Manusia, Edisi pertama, penerbit : Bumi Aksana, Jakarta

Sugiyono, 2011. Metode Penelitian Bisnis. Bandung: Afabeta

Sugiyono, 2012. Statistik Untuk Penelitian. Cetakan ke-21. Penerbit : Afabeta, Bandung 